\title{
Educação do campo e políticas educacionais: avanços, contradições e retrocessos ${ }^{1}$
}

\author{
Éducation de la campagne et politiques éducatives: avancées, contradictions et reculs \\ Field education and educational politics: advances, contradictions and regrecess
}

\author{
Maria do Socorro Silva ${ }^{2}$ \\ Universidade Federal de Campina Grande
}

\begin{abstract}
Resumo: O presente artigo tem como finalidade refletir sobre como a luta por uma política de Educação do Campo, emerge no Brasil, nos últimos 20 anos, como uma estratégia fundante do Movimento da Educação do Campo. Este Movimento que nasceu na contraposição ao modelo de sociedade gerador de assimetrias sociais, políticas e econômicas que marca a história passada e presente do Brasil, e que se posiciona de forma crítica contra o modelo de escola precarizada e descontextualizada que se implantou no campo brasileiro. A abordagem dialética orientou o processo investigativo que teve na análise documental e na revisão de literatura procedimentos fundamentais para construção deste texto. A contradição posta pelo Estado como instrumento de regulação do capital gerou ao longo destes anos um tensionamento na materialização das políticas e programas reivindicados pelo Movimento da Educação do Campo, especialmente neste momento de retrocessos e recuos nos direitos sociais em nosso País, todavia, identificamos conquistas nas práticas educativas, na articulação da diversidade dos sujeitos do campo, das águas e da floresta na luta contra a opressão e pela afirmação de uma territorialização da agricultura familiar e agroecológica.
\end{abstract}

Palavras-Chaves: Educação do Campo. Política Educacional do Campo. Movimento da Educação do Campo.

\begin{abstract}
The current article aims to make a reflection how a policy for Field Education, rises on Brazil, in last 20 years, as a founder strategy of the Field Education Movement. This Movement has emerged against the society model that reproduces social, political and economic asymmetries which marks the past and present Brazil history, and displays a critical position against the precarious and decontextualized school model implemented in Brazilian country. The dialetic approach guided the investigative process that had in the documentary analysis and in the literature review fundamental procedures for the construction of this text. The contradiction posed by the State as an instrument of capital regulation, has generated over the years a tension in the materialization of the policies and programs claimed by the Field Education Movement, especially at this moment of retreats and returns in social rights in our Country. However, we identify achievements in educational practices, in the articulation of the diversity of rural, water and forest subjects in the fight against oppression and by the affirmation of a territorialization of family and agroecological agriculture.
\end{abstract}

Keywords: Field Education. Field Policy. Field Education Movement.

\footnotetext{
${ }^{1} \mathrm{O}$ texto foi originalmente publicado no Livro "Políticas Educacionais e Formação: produção, projetos e ações em Educação", organizado por Sônia da Cunha Urt. Foram feitas atualizações para esta Revista, inclusive no título do texto, considerando os retrocessos nas políticas educacionais no período atual do País.

2 Doutora em Educação e pesquisadora do Núcleo de Pesquisa em Educação do Campo, Formação de Professores/as e Práticas Pedagógicas-NUPERFORP. Membro do Fórum Territorial de Educação Camponesa do Cariri Paraibano. Professora, na Unidade Acadêmica de Educação do Campo/UFCG.
} 
Résumé: Cet article vise à réfléchir sur la façon dont la lutte pour une politique de l’Éducation du champ a émergé au Brésil au cours des 20 dernières années en tant que stratégie fondatrice du Mouvement pour l'Éducation du champ. Ce mouvement est né en opposition au modèle de société qui génère des asymétries sociales, politiques et économiques qui marquent l'histoire passée et présente du Brésil; au même temps, il se positionne de manière critique contre le modèle scolaire précaire et décontextualisé implanté dans la campagne brésilienne. L'approche dialectique a guidé le processus d'enquête, en particulier dans l'analyse documentaire et la revue de la littérature, des procédures fondamentales dans la construction de ce texte.La contradiction posée par l'État en tant qu'instrument de régulation du capital a généré au cours des années une tension dans la matérialisation des politiques et des programmes revendiqués par le Mouvement de l'Éducation du Champ, notamment en ce moment de revers et reculs des droits sociaux dans notre pays. Cependant, nous avons identifié des réussites dans les pratiques éducatives, dans l'articulation de la diversité des sujets paysans, de l'eau et de la forêt dans la lutte contre l'oppression et par l'affirmation d'une territorialisation de l'agriculture familiale et agroécologique.

Mots clés: Éducation du champ. Politique éducationnelle du champ. Mouvement de l’èducation du champ

\title{
Para Início de Conversa
}

\begin{abstract}
Terra, escola, lugar são mais do que terra, escola ou lugar. São espaços e símbolos de identidade e de cultura. Os movimentos sociais revelam e afirmam os vínculos inseparáveis entre educação, socialização, sociabilidade, identidade, cultura, terra, território, espaço, comunidade. Uma concepção muito mais rica do que a redução do direito à educação, ao ensino, informação que pode ser adquirida em qualquer lugar (ARROYO, 2007, p. 163).
\end{abstract}

A história da educação brasileira, explica Ribeiro (1993), tem como característica a consolidação do projeto da sociedade capitalista; ao longo do tempo, ampliou-se a ofensiva da classe dominante para com os sujeitos do campo, em função da defesa do projeto hegemônico na perspectiva da reestruturação e incorporação de novas forças produtivas para a organização do trabalho pelo capital financeiro internacional, por intermédio de empresas transnacionais, que passaram a controlar o mercado agrícola e também os recursos naturais.

A luta pela materialização da escola no campo se constituiu ao longo da história numa luta permanente para superação das desigualdades econômicas, políticas, sociais e culturais vivenciadas pelas populações campesinas, portanto, as assimetrias vividas na sociedade se 
refletiram na inexistência da escola em todos os níveis e modalidades no campo brasileiro ou na sua precarização e desprofissionalização ${ }^{3}$ dos seus docentes.

Reafirmamos assim, a política educacional, como parte constitutiva das mudanças sociais e econômicas, dentro da sociedade capitalista, e não apenas como determinada por estas (PERONI, 2003). E que nesta relação ou processo de disputa de projetos de sociedade o Estado assume um papel fundamental, e redefine sua orientação da política, conforme estas lógicas (HARVEY, 2008), como parte importante de um movimento de correlação de forças de sujeitos (THOMPSON, 1981), que definem o cenário da materialização das políticas educacionais, e da escola.

Com esta perspectiva, este texto buscou evidenciar o surgimento do Movimento da Educação do Campo, dentro de uma relação permanente entre Escola-Estado-Políticas Públicas-Sociedade Civil Organizada, na luta de classes pela disputa de políticas educacionais que respondessem as demandas e direitos dos povos campesinos por uma escolarização básica e superior pública, gratuita, laica, de qualidade social e contextualizada no modo de vida, no trabalho e na cultura camponesa.

\title{
O paradigma da Educação Rural: "a sociologia das ausências”
}

Os estudos de Calazans (1993) demonstraram que, historicamente, a efetivação de projetos educacionais para o campo esteve sucessivamente conectada a projetos econômicos de fortalecimento do capital, indicando que a escola faz parte de uma totalidade, e tende a incorporar a forma como se estruturam as relações de trabalho na sociedade, o que resultou na organização de uma rede escolar voltada para a elite do país, enquanto a maioria da população ficou à margem do acesso aos direitos políticos, civis e sociais, dentre os quais o acesso à escolarização. Conforme o Parecer 36/2001 (BRASIL, CNE/CEB, 2001, p. 5),

\begin{abstract}
a introdução da educação rural no ordenamento jurídico brasileiro remete às primeiras décadas do século XX, incorporando, no período, o intenso debate que se processava no seio da sociedade a respeito da importância da educação para conter o movimento migratório e elevar a produtividade no campo. A preocupação das diferentes forças econômicas, sociais e políticas com as significativas alterações constatadas no comportamento migratório da população foram claramente registradas nos anais dos Seminários e Congressos Rurais realizados naquele período.
\end{abstract}

\footnotetext{
${ }^{3}$ Entendemos desprofissionalização como inexistência de formação inicial e continuada, condições de trabalho precarizada, e não efetivação de piso salarial da categoria, além da sua autonomia organizativa.
} 
O paradigma da Educação Rural emergiu na esfera das políticas governamentais a partir da década de 1930, numa visão dicotômica (urbano/rural, indústria/agricultura, científico/popular, atrasado/moderno), gerando o modelo urbanocêntrico ${ }^{4}$. Segundo os governantes da época, "era preciso educar as populações rurais, povoar e sanear o interior, é a época do lema 'Instruir para Sanear”" (PAIVA, 1985, p. 127). Neste discurso, as cidades ajudam a 'civilizar o homem do campo'. Por isso, a “verdadeira finalidade dessas escolas é a de transformar o homem do campo num homem de ação, ou seja, dar-lhe os predicados de quem mora na cidade" (CALAZANS, 1993, p. 4).

Essa concepção da Educação como redentora da miséria e da pobreza implantou no campo um modelo de escola vinculado ao projeto de 'modernização conservadora', patrocinado por organismos de "cooperação" norte-americana e difundido através do sistema de assistência técnica e extensão rural $^{5}$, com a finalidade de adaptar a população do campo ao projeto desenvolvimentista, que subordinou a agricultura à industrialização, centrada na concepção de que o Brasil para se desenvolver precisaria se industrializar e urbanizar (CALAZANS, 1993).

Desde então o campo passou a ser tratado sistematicamente pelo Estado brasileiro com políticas compensatórias, emergenciais e descontinuadas, não se constituindo como um espaço prioritário para ação institucionalizada de políticas de Estado estruturantes e estruturadoras de uma escola pública que tenha a cidadania, os direitos humanos, o trabalho e a cultura campesina como pilares de sua realização.

A ausência até o inicio do século XXI de política específica para a Educação das populações campesinas, acarretou um funcionamento precário ou a inexistência de escolas em todos os níveis no campo - a oferta da escolarização na maioria das regiões restringiu-se aos anos iniciais do ensino fundamental, geralmente em turmas multisseriadas, e até os dias atuais é comum a oferta da Educação Infantil junto com as turmas do ensino fundamental, sem infraestrutura adequada, proposta pedagógica para trabalhar com a heterogeneidade e

\footnotetext{
4 O termo urbanocêntrico é aqui utilizado para se referir a uma visão na qual a concepção de educação e modelo didático-pedagógico utilizado nas escolas da cidade é transferido para as escolas localizadas nas áreas classificadas pelos órgãos oficiais como rurais, cuja centralidade é a cidade e o processo de urbanização.

${ }_{5}^{5}$ A extensão rural no Brasil surgiu na década de 1940, sob o comando do capital, com forte influência norteamericana e visava superar o 'atraso' da agricultura. Para tanto, havia a necessidade de 'educar" o povo rural, para que ele passasse a adquirir equipamentos e insumos industrializados necessários à modernização de sua atividade agropecuária. Com isso, ele passaria do atraso para a 'modernidade'. O modelo serviu para que a população fosse incluída de forma perversa na dinâmica da sociedade de mercado, aumentando sua produtividade nesse sentido; durante décadas a extensão volta-se para o trabalho com a agricultura patronal e de agroexportação.
} 
formação específica para o professorado que atua com estas turmas. Algumas questões também contribuíram para que isso ocorresse:

$\checkmark$ domínio das oligarquias em várias regiões, que não tinham interesse em que a população tivesse acesso à educação, portanto, a conhecimentos e informações que colocassem em risco a subalternização a que eram submetidas;

$\checkmark$ a concentração das riquezas que gerou durante décadas no campo brasileiro: desemprego, ausência de políticas trabalhistas, agrícolas e sociais, pobreza, êxodo rural, etc;

$\checkmark$ a desorganização interna da política, não por acaso, apresentando fragmentação e justaposição de ações, esforços humanos, investimentos físicos, financeiros das politicas educacionais envolvendo ao mesmo tempo, espaços e sujeitos, sem nenhum planejamento estratégico;

$\checkmark$ a carência de recursos didático-pedagógicos, a precariedade da infraestrutura das escolas, a desvalorização profissional dos docentes e as péssimas condições de trabalho;

$\checkmark$ a subalternização dos Povos do Campo não possibilitava uma compreensão do papel e o direito da escola na comunidade rural, o que enfraqueceu a pressão e a mobilização das comunidades junto aos órgãos governamentais pelo direito a escolarização, o que naturalizou no país, a ideia que se resolvia essa precarização das escolas com o seu fechamento.

Segundo Whitaker e Antuniassi (1992, p. 13), o tipo de escolarização oferecida aos diferentes grupos sociais do mundo urbano e rural, tem três características fundamentais:

$\checkmark$ é urbanocêntrica, unicamente voltada aos conteúdos formados e informados pelo processo de urbanização e industrialização; o ponto de partida e de chegada do conhecimento é a cidade, apresentada como superior e moderna. O mundo rural precisa ser abandonado por quem quer vencer na vida, uma vez que nele não há chance de se progredir;

$\checkmark$ é sociocêntrica, voltada aos interesses de certas classes sociais, não considerando a diversidade dos sujeitos sociais existentes no campo e na cidade, a sua cultura, as suas diversas formas de organizar o trabalho e a vida;

$\checkmark$ é etnocêntrica, privilegiadora dos conhecimentos relativos ao mundo ocidental industrializado, de uma forma de pensar e de um estilo de vida eurocêntrico, onde os valores e a cultura camponesa são considerados como atrasados, conservadores, 
criando, assim, estereótipos com relação à população do campo e ao seu modo de viver e de pensar.

Santos (2005) denomina de "Sociologia das ausências", essa lógica que produz a não existência de uma dada realidade, entidade ou agentes, a partir de sua desqualificação, que a torna invisível ou descartável. Essa visão política e epistemológica fez com que a realidade do campo, seus sujeitos sociais e a escola que lhe foi destinada fossem tratados pela racionalidade hegemônica, como

[...] o ignorante, o residual, o inferior, o local e o improdutivo. Trata-se de formas sociais de inexistência porque as realidades que elas conformam estão presentes apenas como obstáculos em relação às realidades científicas, avançadas, superiores, globais ou produtivas. São, pois, partes desqualificadas de totalidades homogêneas que, como tal, confirmam meramente o que existe e tal como existe. São o que existe sob formas irreversivelmente desqualificadas de existir. (SANTOS, 2005, p. 14-15).

Essa racionalidade que o autor denomina de razão metonímica, que se reivindica “ $[\ldots .$. como a única forma de racionalidade e, por conseguinte, não se aplica a descobrir outros tipos de racionalidade ou, se o faz, fá-lo apenas para torná-las em matéria-prima” (SANTOS, 2005, p. 6), pauta durante décadas a elaboração das políticas educacionais do país a partir de um modelo globalizante e universalizante, na medida em que nega a diversidade dos sujeitos sociais.

A luta pelo direito à igualdade, a partir das diferenças, "traduz a necessidade dos grupos sociais assimetricamente situados em acessar a educação" (SILVA, 2000, p. 81), e questiona os estereótipos sociais, sexuais, étnicos e culturais homogeneizadores, na perspectiva de construir um diálogo intercultural permanente como ponto de partida e de chegada para construção de uma política educacional e de uma sociedade multicultural que

[...] não se constitui na justaposição de culturas, muito menos no poder exacerbado de uma sobre as outras, mas na liberdade conquistada, no direito assegurado de mover-se a cada cultura no respeito uma da outra, correndo risco livremente de ser diferente, sem medo de ser diferente, de ser cada uma para si, somente como se faz possível crescerem juntas e não na experiência da tensão permanente provocada pelo todo-poderoso uma sobre as demais, proibidas de ser (FREIRE, 1995, p. 156).

A própria Educação Rural que ainda permanece no campo brasileiro não é mais a mesma, porque dimensões presentes na concepção da Educação do Campo, ao circular pelas 
políticas e programas governamentais, dos municípios e estados, terminam influenciando nas escolas das redes, na formação do professorado, na proposição e reinvindicação dos movimentos sociais com princípios, fundamentos, marcos normativos da Educação do Campo, o que gera questionamentos da prática hegemônica, e suscita o interesse do professorado sobre o Movimento da Educação do Campo e suas práticas educativas.

Esse Movimento possibilita também o questionamento de uma perspectiva saudosista, romântica do território campesino como o lugar da paz, da harmonia, da inexistência de conflito, o que comprometeu uma compreensão crítica das contradições vivenciadas no território camponês dentro da sociedade capitalista. Essa posição que subestima a evidência dos conflitos que mobilizam as forças econômicas, sociais e políticas em torno da posse da terra no país, escamoteia a desterritorialização e subalternização sofrida pelos Povos do Campo ${ }^{6}$, com a colonização, e a permanência da opressão com formas de colonialidade de poder e de saber.

\section{A Educação do Campo como direito: a afirmação da diversidade}

No final da década de 1970, a luta dos Povos Indígenas pela terra, desencadeou iniciativas que favoreceram a articulação entre aldeias e povos nas assembleias indígenas, como forma de solidariedade interétnica e fortalecimento dos movimentos e organizações indígenas: a criação de entidades de apoio à causa indígena, que estimulou o processo de reflexão crítica sobre o processo de exploração colonialista; e a construção de alianças com diferentes entidades e organizações, que desembocaram na construção da educação escolar indígena como direito, afirmando as identidades étnicas, o fortalecimento das memórias históricas, a valorização da ancestralidade e da cosmovisão dos Povos Indígenas.

A luta dos Povos Indígenas pela Educação Intercultural também serviu de referência para que outros Povos do Campo começassem, a partir do final da década de 1980, a inserir, nas suas pautas de mobilizações pela democratização do país, a luta por direitos humanos, Reforma Agrária, Políticas Agrícolas e Sociais para o Campo Brasileiro; dentre estes o direito à Educação, se afirma como ação coletiva e organizada dos movimentos sociais populares. $\mathrm{O}$

\footnotetext{
${ }_{6}$ O termo Povos do Campo é usado em diferentes documentos de movimentos sociais para se referir à heterogeneidade dos sujeitos sociais do campo: agricultores (as) familiares, assentados (as) e acampados (as), reassentados, ribeirinhos, extrativistas, pescadores artesanais, comunidades quilombolas, caiçaras, comunidades de fundo de pasto, pantaneiros, vaqueiros, gerazeiros, faxinalenses e tantos outros que produzem e reproduzem sua vida numa relação direta com a terra, a floresta e as águas considerando suas diferentes modulações de gênero, geração, raça, etnia e orientação sexual.
} 
processo de redemocratização do país, a partir do início dos anos de 1980, assumido pelo Campo Popular ${ }^{7}$, tem um papel protagonista na proposição e formulação de práticas e políticas, que se contraponham ao modelo hegemônico de sociedade e da educação.

A luta histórica por acesso e permanência com sucesso na escola ganha novo contorno a partir da década de 1990, com a expectativa de democratização da gestão, redução das desigualdades sociais, participação política da população na conquista de seus direitos, de justiça social e de profissionalização dos educadores(as). Assim, os movimentos sociais desempenharam um papel decisivo nos rumos das políticas educacionais, no caso, da Educação do Campo. "No vazio e na ausência dos governos os próprios movimentos tentam ocupar esses espaços, mas cada vez mais cresce a consciência do direito e a luta pela Educação do Campo como política pública”. (ARROYO; CALDART; MOLINA, 2004, p. 14).

As mobilizações para formulação da Constituição Federal de 1988, pela democratização do país e afirmação de uma cultura de direitos, garantiram importantes conquistas populares e espaços de participação na legislação, ao incorporar o princípio da participação direta na administração pública, além da criação de conselhos gestores como forma de intervenção popular nas políticas públicas do país. Com efeito, a Constituição Federal de 1988, preconizou o direito ao acesso universal a serviços e bens coletivos. Para isso, foram criados os mecanismos institucionais para os processos descentralizadores que se seguiriam e ampliaram-se as perspectivas da participação cidadã na concepção e efetivação das políticas públicas.

A Educação do Campo nasceu tomando posição contra a lógica e o modelo de desenvolvimento gerador de assimetrias sociais, políticas e econômicas construídas historicamente no Brasil. O entendimento de que o campo comporta uma diversidade de agroecossistemas, etnias, culturas, relações sociais, padrões tecnológicos, formas de organização social e política, e da necessidade de fortalecer uma ruralidade pautada pela territorialização da agricultura familiar/camponesa/agroecológica, que se contrapõe ao discurso hegemônico da modernização pela urbanização e pelo agronegócio ${ }^{8}$.

A Educação do Campo se afirma ao longo destes 20 anos como uma concepção e prática educativa da classe trabalhadora do campo, em sua diversidade de territórios e sujeitos:

\footnotetext{
7 Segundo Paludo (2009, p. 46), “os campos populares constituíram-se como movimentos contra hegemônicos (muitas vezes designado, nos textos, como esquerda) e se orientaram por utopias de transformação social, às quais foram atribuídas as mais diversas denominações, dentre elas: projeto histórico; projeto libertador; novo contrato social; nova sociedade; sociedade sem oprimidos e opressores; projeto alternativo de sociedade e sociedade socialista”.

8 Agronegócio é uma palavra nova, da década de 1990. É também uma construção ideológica para tentar mudar a imagem latifundista da agricultura capitalista. Procura representar a imagem da produtividade, da modernização, da geração de riquezas para o país a partir da exportação e geração de commodities.
} 
agricultores/as familiares, assalariados/as, posseiros, assentados/as, ribeirinhos, caiçaras, extrativistas, pescadores artesanais, indígenas, remanescentes de quilombolas, comunidades de fundo de pasto, gerazeiros, enfim, todos os Povos do Campo brasileiro. Essa concepção está expressa no art. 2 , $_{\text {}}$ único das Diretrizes Operacionais para a Educação Básica nas Escolas do Campo (BRASIL, 2002), quando diz que:

a identidade da escola do campo é definida pela sua vinculação às questões inerentes à sua realidade, ancorando-se na temporalidade e saberes próprios dos estudantes, na memória coletiva que sinaliza futuros, na rede de ciência e tecnologia disponível na sociedade e nos movimentos sociais em defesa de projetos que associem as soluções exigidas por essas questões à qualidade social da vida coletiva no país.

As práticas educativas construídas pelos movimentos campesinos, quilombolas e organizações correlatas construíram a concepção de Educação do Campo, interagindo com as outras dimensões da vida do campo. Esse processo aconteceu com a participação de diferentes entidades, dentre as quais podemos destacar: Movimento dos Trabalhadores Sem Terra (MST), da Confederação Nacional dos Trabalhadores(as) Rurais e na Agricultura Familiar (CONTAG), da União Nacional das Escolas Famílias Agrícolas no Brasil (UNEFAB), da Rede de Educação do Semiárido Brasileiro (RESAB), principalmente com a articulação das práticas pedagógicas existentes no campo, possibilitando a construção de uma rede que se movimenta pela luta, pela prática educativa e pela reinvindicação dos direitos.

Em 1998, estes movimentos sociais em parceria com as universidades, organizações não governamentais e pastorais sociais, articularam nacionalmente o Movimento por uma Educação do Campo. O Movimento não apenas articulou as diversas práticas educativas existentes no país, como também assumiu o protagonismo na proposição e reinvindicação de políticas públicas que priorizem a superação de precariedade das escolas, bem como a implantação de um sistema escolar que atenda aos interesses da população (ROCHA, 2004).

O Movimento da Educação do Campo, em seu processo de mobilização pela afirmação e fortalecimento das práticas pedagógicas das Escolas do Campo, instigou as políticas públicas a compreenderem o campo como um espaço emancipatório, como um território fecundo de construção da democracia e da solidariedade, e de lutas pelo direito a terra, às águas, a floresta, à soberania alimentar, à saúde, à educação, ao meio-ambiente sustentável, enfim, um lugar de direitos. Assim,

[...] trata-se um movimento que teve início antes no seio da sociedade civil organizada, mais propriamente, neste caso, no seio das organizações sociais 
do campo, em forma de experiências de educação popular na formação de seus quadros dirigentes e de suas bases e, mais recentemente, em forma de reinvindicação de escola pública de qualidade como "direito de todos e dever do Estado" - síntese do conceito de política pública. Assim, seria mais apropriado dizer que o MEC abre espaço na máquina estatal para as vozes desses sujeitos que já vinham sedimentando as bases de uma política pública de Educação do Campo (MUNARIM, 2006, p. 16).

O Movimento da Educação do Campo vai se constituir como um movimento (um processo de luta, de mobilizações, de práticas sociais e educativas) e um paradigma (uma teoria, uma ideologia, elaborações discursivas), tornando-se uma posição política, pedagógica e epistemológica de uma educação que busca contribuir para que os sujeitos campesinos tenham o seu direito a uma Escola no lugar onde vivem e que tomem como ponto de partida e de chegada, as suas realidades sociais, econômicas, culturais e ambientais.

No quadro 01 podemos visualizar a multidimensionalidade deste Movimento que se articula a nível nacional a partir do protagonismo dos movimentos sociais do Campo, da parceria com Universidades e com organizações não governamentais vinculadas a Educação Popular.

\section{Quadro 01 - Dimensões e atuação do Movimento da Educação do Campo}

\begin{tabular}{|c|c|}
\hline Dimensões & Atuação \\
\hline Propositiva & Apresenta formulações para elaboração das políticas educacionais. \\
\hline Gestora & $\begin{array}{l}\text { Participa de Fóruns e Comitês na fiscalização e controle social das } \\
\text { políticas públicas. }\end{array}$ \\
\hline Formativa & $\begin{array}{l}\text { Realiza a formação dos sujeitos sociais envolvidos nas práticas } \\
\text { educativas e aços organizativas da Educação do Campo. }\end{array}$ \\
\hline Política & $\begin{array}{l}\text { Mobiliza os atores sociais para a defesa e luta pelos direitos dos } \\
\text { sujeitos do campo a escolarização em todos os níveis no campo. }\end{array}$ \\
\hline Epistemológica & $\begin{array}{l}\text { Propõe uma nova visão de conhecimento sistêmico e dialético } \\
\text { superando a fragmentação e a descontextualização. }\end{array}$ \\
\hline Pedagógica & $\begin{array}{l}\text { Materializa práticas educativas escolares e não escolares em todo o } \\
\text { país, constituindo uma nova teoria pedagógica, na qual, diferentes } \\
\text { sujeitos sociais, territórios, linguagens e saberes se entrelaçam. }\end{array}$ \\
\hline Metodológica & $\begin{array}{l}\text { Constrói itinerários curriculares nos quais a alternância possibilita a } \\
\text { articulação entre teoria e prática e o diálogo entre diferentes tempos, } \\
\text { espaços e saberes. }\end{array}$ \\
\hline
\end{tabular}

À medida que a escola possibilita a construção de conhecimentos e a problematização da realidade, que se torna conteúdo pedagógico básico das escolas, numa perspectiva epistemológica e metodológica de construção coletiva do conhecimento, a partir dos desafios da prática, 
[...] assume, assim, a função social de contribuir para a transformação das realidades que se traduzem em assimetrias econômicas, sociais, políticas e culturais a que estão submetidas os sujeitos sociais do campo, fato evidenciado quando temos denunciado a grave situação vivida pelo povo brasileiro que vive no e do campo, e as consequências sociais e humanas de um modelo de desenvolvimento baseado na exclusão e na miséria da maioria. Temos denunciado os graves problemas da educação no campo e que continuam hoje (II CONFERENCIA NACIONAL DE EDUCAÇÃO DO CAMPO, 2004).

A II Conferência Nacional de Educação do Campo (2004) ampliou esse debate e reafirmou a necessidade de uma política específica de formação dos profissionais da Educação do Campo. As entidades participantes da Conferência colocaram a necessidade de superar a desigualdade social e a miséria, existentes no campo, e afirmam a importância de fortalecimento da produção camponesa/familiar, que se constitui num projeto de desenvolvimento sustentável e na superação da dicotomia e subordinação do campo pela cidade. Consequentemente, os princípios políticos que orientam as propostas pedagógicas da Educação do Campo apostam na construção de relações de poder equitativas e justas nos diferentes âmbitos da vida:

\footnotetext{
lutamos por um projeto de sociedade que seja justo, democrático e igualitário; que contemple um projeto de desenvolvimento sustentável do campo, que se contraponha ao latifúndio e ao agronegócio e que garanta: a realização de uma ampla e massiva reforma agrária; demarcação das terras indígenas; o fortalecimento e expansão da agricultura familiar/camponesa; as relações/condições de trabalho, que respeitem os direitos trabalhistas e previdenciários x dos trabalhadoras e trabalhadores rurais; a erradicação do trabalho escravo e da exploração do trabalho infantil; o estímulo à construção de novas relações sociais e humanas, e combata todas as formas de discriminação e desigualdade fundadas no gênero, geração, raça e etnia; a articulação campo - cidade, o local - global (II CONFERENCIA NACIONAL DE EDUCAÇÃO DO CAMPO, 2004).
}

Com essa afirmação, o Movimento da Educação do Campo não está ratificando o discurso de que cabe à escola a responsabilidade para fazer a transformação social, pois "a natureza de sua materialidade não permite isto" (CALDART, 2000, p.179). No entanto, os valores, os princípios, os rituais, as relações e interações dos sujeitos com os conhecimentos vivenciados na organização e dinâmica do trabalho educativo possibilitam um novo modo de vida, ao cotidianizar e institucionalizar relações sociais, pautadas na participação, autonomia, cooperação e equidade. 
Uma educação que trabalhe pelo diálogo entre as culturas (interculturalidade) por meio da realização dele na prática pedagógica, que segundo Freire (1978), favorece a busca de pontos de convergência na diversidade. Por isso, os processos educativos necessitam ir além da escola, interagindo com o contexto de vida dos sujeitos sociais, do seu trabalho e de suas organizações. Sendo assim,

queremos uma escola em movimento, em ação. Onde todos estejam envolvidos em algum tipo de trabalho, criando, inovando, conhecendo e pesquisando. (...) precisamos que os nossos filhos queiram permanecer no campo e que saibam lutar para que esta permanência seja com dignidade e com muita alegria de viver. (...) Preparar as novas gerações para as mudanças sociais. Para lutar pela sociedade sem explorados nem exploradores. E para viver nesta nova sociedade (DOSSIÊ MST, 2005, p. 95).

A Educação, como direito dos sujeitos do campo, tem como ponto de partida a igualdade e o reconhecimento dos direitos humanos, e o exercício da cidadania passa também pela busca da equidade no acesso à educação, ao emprego, à saúde, ao meio ambiente saudável, a uma reforma agrária ampla e massiva e ao combate a todas as formas de preconceito e discriminação por motivo de raça/etnia, sexo, orientação religiosa, cultura, aparência ou condição física, mas significa também o respeito às diferenças dos sujeitos e da sua realidade.

\section{A Educação do Campo como direito: a luta por marco regulatório}

O Estado e a Sociedade Civil são perpassados por correlações de forças de projetos societários distintos, o que faz com que a política educacional seja parte constitutiva deste conflito, e define o papel do Estado com os direitos sociais, dentre estes os da Educação que foram ao longo dos últimos anos materializados em diferentes programas e ações - numa perspectiva de construção de uma política pública.

A luta pela assunção da educação do campo é multidimensional e tem acontecido em diferentes frentes: na produção criativa de práticas e experiências concretas, na formulação de campanhas, programas e políticas públicas específicas, na produção de conhecimentos, na circulação de uma ordem discursiva pertinente e na proclamação de atos jurídicos próprios. Desse modo, ela tem conquistado assento no cotidiano pedagógico, na agenda dos governos municipais, estaduais e federal, na pesquisa (MIRANDA, 2013, p. 34).

Para o atendimento de históricas demandas dos povos do campo pela expansão da oferta e a elevação da qualidade das escolas do campo, destacam-se algumas ações 
governamentais, em atendimento ao disposto no artigo $3^{\circ}$, da Lei de Diretrizes e Bases da Educação Nacional (Lei n. 9394/96), tais como a realização de duas Conferências Nacionais por uma Educação Básica do Campo, em 1998 e 2004; a aprovação, pelo Conselho Nacional de Educação (CNE), das Diretrizes Operacionais para a Educação Básica nas Escolas do Campo, em 2002, e das Diretrizes Complementares, Normas e Princípios para o Desenvolvimento de Políticas Públicas de atendimento da Educação Básica do Campo, em 2008 e do Decreto Presidencial de 2010 (FIGURA 1).

Figura 01 - Principais leis da Educação do Campo com suas ênfases
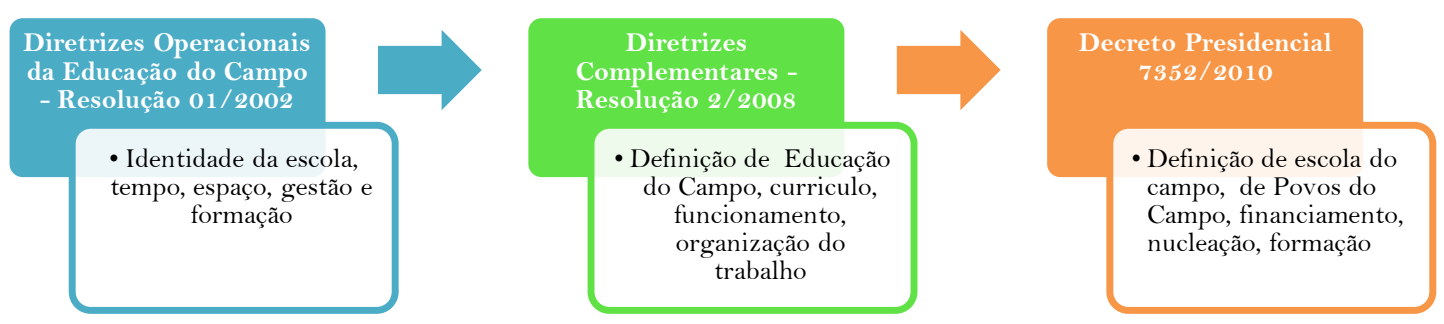

Fonte: Sistematizado pela autora, 2017.

Ao longo dos anos este marco normativo foi divulgado de diferentes formas entre educadores/as do campo, gestores/as municipais e estaduais, e movimentos sociais, na busca de constituir um lastro político importante; a constituição de comitês e fóruns estaduais, municipais e territoriais de Educação do Campo foram espaços importantes de proposição, concertação e reinvindicação destas políticas, bem como, a implementação de programas e ações desencadeadas principalmente pelo governo federal, se constituíram em políticas afirmativas, que possibilitaram a materialização de ações na Educação Básica e Superior do País, todavia, permeadas pelas contradições e tensões entre o Estado e as diferentes instituições da Sociedade Civil - o que resultou numa fragilidade para sua universalização nos sistemas municipais e estaduais de Educação.

O modelo macroeconômico não mudou com a mudança de governo (2003-2015), manteve sua lógica centrada nos ganhos especulativos ligados ao capital financeiro, e mesmo com a ampliação das políticas sociais, o projeto de educação nacional, manteve-se sobre forte 
influência das perspectivas do neotecnicismo, fazendo mais uma vez a transferência de conceitos da industrialização e da administração para se pensar a escola, associada às noções de habilidades e competências, às tecnologias dos sistemas de ensino e à produção de materiais pelas editoras e grupos privados.

O discurso do direito restrito à aprendizagem do básico perpetua-se por um lado à exclusão dos processos de formação humana, e com fortes ligações com os interesses do mercado de trabalho. Neste sentido, acirrou os focos de tensões e contradições, postos por Caldart, (2009, p. 47):

destaco dois grandes focos de tensões ou de concentração das contradições: o primeiro e principal está na própria dinâmica do campo dentro da dinâmica do capitalismo e do acirramento das contradições sociais que vem do movimento de expansão do capital, brutalmente acelerado no campo nestes últimos anos. O segundo diz respeito à relação tensa (que na sociedade capitalista não tem como não ser contraditória) entre Pedagogia do Movimento e políticas públicas, relação entre movimentos sociais com projeto de transformação da sociedade e Estado.

A fragilidade das políticas educacionais do campo evidencia como predominam os interesses capitalistas nos direcionamentos das ações estatais, inclusive no direcionamento das políticas educacionais. Mesmo que o poder político do Estado seja assumido por governos de diferentes vertentes ideológicas, a essência das políticas se mantém, uma vez que não rompem com a lógica do capital (MÉSZÁROS, 2005).

A reestruturação que vem ocorrendo no sistema capitalista impõe um movimento de liberalização das relações de e no mercado, e um quadro de retrocesso político inigualável. Para se acomodar as inúmeras mudanças provocadas pela nova ordem social gestada sob o comando do capital financeiro, novas relações foram estabelecidas entre Estado e Sociedade, com o fim da proposta constitucional de aliança entre direitos e equidade e com a degradação da proteção social.

As políticas educacionais incorporam cada vez mais, a perspectiva da educação como mercadoria, a produção do conhecimento assume cada vez mais um aspecto comercial, assim as ações educacionais assumem o direito à aprendizagem, e não o direito a educação como formação humana, como principio central para formulação das diferentes políticas: reforma do 
ensino médio, sistema nacional de avaliação, base nacional comum curricular, dentre outras, são as principais orientações dos empresários da educação para as políticas educacionais ${ }^{9}$.

A retirada dos movimentos sociais da gestão das políticas educacionais foi sinalizando para este momento que vivemos atualmente, ao mesmo tempo, ações específicas da Educação do Campo, se redimensionam, como por exemplo, Programa Saberes da Terra, ou se fragiliza - Pronera e Licenciatura em Educação -, e se acentuam os processos de fechamento das escolas nas comunidades rurais.

Assim, num cenário de perda de direitos e de território, de ameaça da democracia, a falta de atendimento às demandas de educação, o Movimento da Educação do Campo, é chamado a afirmar cada vez mais a "Educação do Campo como direito, e não mercadoria”, e a fortalecer a campanha contra o fechamento das escolas no campo, na perspectiva do direito do povo campesino permanecer em suas comunidades, bem como as políticas de escolarização e formação docentes desenvolvidas pelo Pronera e pela Licenciatura em Educação do Campo.

\section{Considerações Finais}

Neste texto apresentamos alguns elementos para o debate sobre as políticas educacionais na Educação do Campo. Essa questão necessita ser analisada dentro do contex to da luta pela democratização das políticas educacionais, vivenciada nos últimos anos, que articulou o debate sobre o acesso à escola em todos os níveis, a permanência com sucesso, a forma como a escola constrói e produz o conhecimento e organiza sua gestão como estratégicos para a construção de uma Educação Pública no País. No entanto, também verificamos a presença cada vez maior do privado mercantil definindo a educação pública, e como isto trouxe contradições e retrocessos para as conquistas do Movimento da Educação do Campo.

A estreita vinculação do movimento educativo com a sociedade coloca um problema crucial dos limites e das possibilidades da educação como instrumento de regulação do capital ou de mudança social. Essa limitação da educação precisa ser entendida dentro das contradições do Estado na sociedade capitalista, do contexto social e da escola, ou seja, nos encaminhamentos das lutas políticas e ações coletivas, da construção de novas sociabilidades, das relações com a natureza e de uma formação humana emancipatória; essa disputa ocorre

\footnotetext{
9 No Brasil, verificamos o protagonismo de empresários através do Movimento Todos pela Educação (TPE), criado em setembro de 2006. A estratégia de atuação do TPE engloba o monitoramento e análise dos indicadores educacionais oficiais, definindo a agenda educacional no país e avaliando os resultados.
} 
dentro da materialidade do capitalismo que busca frear todas as perspectivas de mudanças e emancipação do ser humano. E é dentro desta abordagem que nos situamos na compreensão do papel da escola permeada pelo movimento contraditório da sociedade e da prática interna dos seus sujeitos.

A necessidade de formação permanente, o fortalecimento dos espaços de debates e proposições da escola do campo, a articulação com os movimentos sociais para se pensar estratégias de resistência das práticas educativas do campo seja na educação básica, superior e na educação não escolar foram pautas permanentes dos movimentos sociais do campo durante todo este período.

A Educação torna-se mediadora para a construção desta sociabilidade plenamente emancipada, portanto, atravessada pelos antagonismos sociais da sociedade de classes em que vivemos, pois, os discursos neoliberais, cheios de 'modernidade', não têm a força suficiente para acabar com as classes sociais e decretar a inexistência de interesses antagônicos entre elas, como não tem forças para acabar com os conflitos e a luta entre elas.

Como se viu no decorrer do texto, discutir sobre políticas educacionais do campo, passa necessariamente pela organização e proposição do Movimento da Educação do Campo. Ao longo da última década, tivemos conquistas importantes com o marco normativo que reconhece a especificidade e o direito dos povos campesinos, com o fortalecimento de redes de educação, fóruns de educação do campo, grupos de pesquisas, a existência da Licenciatura em Educação do Campo, a estruturação de Programas de Pós-graduação em Educação do Campo ou com linhas de pesquisa neste campo temático, as práticas educativas desenvolvidas pelo Pronera, e a persistência de programas, como a Escola da Terra, de manter os fundamentos e princípios da Educação do Campo.

A resistência para manter os direitos conquistados, de assegurar à continuidade das escolas nas comunidades rurais, de reivindicar a participação dos movimentos sociais no controle social das políticas educacionais do campo, se tornou bandeira de luta fundamental em tempos de enquadramento neoliberal e neoconservador da sociedade brasileira.

Certamente, uma questão importante neste cenário é a organização do Fórum Nacional de Educação do Campo - FONEC, como espaço de articulação dos sujeitos sociais coletivos, educadores/as e militantes da Educação do Campo, pautados pelo princípio da autonomia em relação ao Estado, que desenvolvem uma luta sistemática para

primar, antes de tudo, pelo cumprimento do direito humano inalienável e indivisível à educação de qualidade, a todos os que vivem no e do campo, 
salvaguardadas, sempre, a diversidade cultural e as especificidades sociais e ambientais da vida e do trabalho dos povos do campo (FONEC, 2010, s.p.).

No cenário de retrocessos dos direitos, o fortalecimento da Escola do Campo, dos seus profissionais, a sua afirmação no território camponês, como um espaço relevante para a prática, reflexão e construção de conhecimentos contextualizados, críticos e comprometidos com a realidade dos/as educandos/as, suas famílias e comunidades, e principalmente com um projeto societário de justiça social, de sustentabilidade, de convivência com os biomas e de fortalecimento da agricultura familiar e agroecológica, ainda são tarefas a se cumprir.

\section{Referências}

ARROYO, Miguel. Que Educação Básica para os Povos do Campo? Palestra proferida no Seminário Nacional “Educação Básica nas Áreas de Reforma Agrária do MST”, realizado em Luziânia/GO de 12 a 16 de setembro de 2005.

Por um Tratamento Público da Educação do Campo. Por uma Educação do Campo: Contribuições para a construção de um projeto de Educação do Campo. Articulação Nacional por uma Educação do Campo: Brasília - DF, 2004.

. Miguel Gonzalez. Políticas de formação de educadores (as) do campo. Cad. CEDES, Ago 2007, vol.27, no. 72, p.157-176.

ARroyo, M. G.; CALDART, R. S.; MOLinA, M. C. (Org.). Por uma educação do campo. Petrópolis: Vozes, 2004.

BRASIL. Constituição da República Federativa do Brasil. Brasília: Senado, 1988.

Lei n. 9394/96. Estabelece as diretrizes e bases da educação nacional. Brasília, 1996.

CNE/CEB. Parecer n. 36/2001. Diretrizes Operacionais para a Educação Básica nas Escolas do Campo. Brasília, 2001.

CNE/CEB. Resolução n. 01/2002. Institui Diretrizes Operacionais para a Educação Básica nas Escolas do Campo. Brasília, 2002.

CNE/CEB. Parecer n. 23/2007. Consulta referente às orientações para o atendimento da Educação do Campo. Brasília, 2007.

CNE/CEB. Resolução n. 2, de 28 de abril de 2008. Estabelece as diretrizes complementares, normas e princípios para o desenvolvimento de políticas públicas de atendimento da Educação Básica do Campo. Brasília, 2008.

CALAZANS, Maria Julieta Costa. Para compreender a educação do Estado no Meio Rural: traços de uma trajetória. In: THERRIEN; DAMASCENO, Maria Nobre (Coord.). Educação e Escola no campo. Campinas: Papirus, 1993. 
CALDART, Roseli Salete. Educação do Campo: notas para uma análise de percurso Trabalho Educação e Saúde, Rio de Janeiro, v.7 n.1, p.35-64, mar./jun.2009.

DOSSIÊ MST ESCOLA. Documentos e Estudos 1990-2001. Caderno de Educação, n. 13. Edição Especial. ITERRA/MST. Rio Grande do Sul, 2005.

FONEC. Carta de Criação do Fonec. Brasília. 2010.

FREIRE, Paulo. Pedagogia do Oprimido. 5. ed. Rio de Janeiro: Paz e Terra, 1978.

Educação como prática de liberdade. Rio de Janeiro. Paz e Terra, 1982.

Pedagogia da Esperança. Um reencontro com a Pedagogia do Oprimido. 15. ed. Rio de Janeiro: Paz e Terra, 2008.

FRIGOTTO, Gaudêncio. A produtividade da escola improdutiva: um (re)exame das relações entre educação e estrutura econômica social capitalista. São Paulo: Cortez, 1984.

HARVEY, D. O neoliberalismo: história e implicações. São Paulo: Loyola, 2008.

MÉSZÁROS, I. A educação para além do capital. São Paulo: Boitempo, 2005.

MUNARIM, Antônio. Elementos para uma política pública de Educação do Campo. In: MOLINA, Mônica (Org.). Educação do Campo e pesquisa: questões para reflexão. Brasília, MDA, 2006.

PAIVA, Marilda Pereira. Educação Popular e educação de adultos. 3. ed. São Paulo: Edições Loyola, 1985.

PALUDO, Conceição. Educação Popular - Dialogando com Redes Latino-Americanas (20022003). In: PONTUAL, Pedro; IRELAND, Timothy (Org.). Educação Popular na América Latina: diálogos e perspectivas. Brasília: Ministério da Educação: UNESCO, 2009.

PERONI, Vera Maria Vidal. Política educacional e papel do Estado no Brasil dos anos 90. São Paulo: Xamã, 2003.

PERONI, V.; ADRIÃO, T. A relação público/privado e a gestão da educação em tempos de redefinição do papel do Estado. In: ADRIÃO, T.; PERONI, V. Público e privado na educação: novos elementos para o debate. São Paulo, Xamã, 2008.

RIBEIRO, Maria Luísa. História da Educação Brasileira: a organização escolar. 13. ed. Campinas: Autores Associados, 1993.

ROMANELLI, Otaíza. História da Educação no Brasil. Petrópolis: Vozes, 1978.

ROCHA, Eliene Novaes. PASSOS, Joana Célia dos. CARVALHO, Raquel Alves de. Texto Base Educação do Campo: um olhar panorâmico. II Conferência Nacional de Educação do Campo. Luziania- GO, 2004. 
Revista Educação e Políticas em Debate - v. 7, n.1, p. 23 - 41 - jan./abr. 2018 - ISSN 2238-8346

SANTOS, Boaventura de Souza. Um discurso sobre as Ciências. 4 ed. São Paulo: Cortez, 2005.

SILVA, Maria do Socorro. Os saberes do professorado rural: construídos na vida, na lida e na formação. Dissertação (Mestrado em Educação). UFPE, Recife, 2000.

THOMPSON, E. P. A miséria da teoria ou um planetário de erros. Uma crítica ao pensamento de Althusser. Rio de Janeiro: Zahar Editores, 1981.

WHITAKER, D. C. A.; ANTUNIASSI, M. H. R. Escola pública localizada na zona rural: contribuições para a sua estruturação. Cadernos Cedes. n.33, p.9-42, 1992. 